\title{
RESÍDUOS SÓLIDOS DO MUNICÍPIO DE TEFÉ (AMAZONAS): CARACTERIZAÇÃO DO PROBLEMA E POTENCIAL ECONÔMICO
}

\author{
SOLID WASTE OF THE MUNICIPALITY IN TEFÉ \\ (AMAZONAS): PROBLEM CARACTERIZATION AND \\ ECONOMIC POTENTIAL
}

\section{Diego Pedroza Guimarães; Rafael Bernhard}

Universidade do Estado do Amazonas/Centro de Estudos Superiores de Tefé UEA/CEST, Estrada do Bexiga, 1085, Jerusalém, CEP: 69.552-315, Tefé - AM. diego.guima1@hotmail.com/rafbernhard@gmail.com

\begin{abstract}
RESUMO
Os resíduos sólidos gerados pela sociedade humana, geralmente vistos apenas como fonte de problemas ambientais, podem ser reutilizados, gerando trabalho, renda e diminuindo a velocidade de esgotamento dos recursos naturais. O presente estudo visou classificar e quantificar os resíduos sólidos descartados por residências e comércios do município de Tefé, Amazonas, além de avaliar possíveis ganhos financeiros por meio de vendas para reciclagem. Como resultado, estimou-se que cerca de $27 \%$ de todos os resíduos produzidos podem ser reciclados, gerando renda financeira que poderia fomentar cooperativas de catadores gerando renda e emprego. Os residentes e comerciantes demonstram desconhecer os benefícios gerados pela reciclagem, bem como o impacto ambiental causado pelo resíduo. Somente alguns poucos órgãos e instituições proporcionam iniciativas de ações quanto ao aproveitamento e reciclagem, e a maioria aponta dificuldades para por em prática projetos e ações voltadas aos resíduos sólidos.
\end{abstract}

Palavras-chave: Resíduos Sólidos. Reciclagem. Potencial Econômico. Tefé. Amazonas.

\begin{abstract}
The solid waste generated by human society, generally seen as environmental problem source, can be re-utilized, generating jobs, money and diminishing natural resources extracting rate. The present study aimed to classify and quantify the solid waste disposed of by residents and business owners in Tefé, Amazon, to determine possible financial gains from the sale for recycling. According to the result was estimated that about of $27 \%$ all produced waste can be recycled, generating financial income and job. Residents and business owners are unaware of the benefits generated by recycling as well as the environmental impact caused by waste. Only a few agencies and institutions provide affirmative actions regarding recovery and recycling, and most point to difficulty to set aside projects and actions aimed at solid waste.
\end{abstract}

Key-words: Solid Waste. Recycling. Economic Potential. Tefé. Amazon. 


\section{INTRODUÇÃO}

O crescimento da população urbana, juntamente com novos padrões de consumo tem ocasionado o aumento da geração de resíduos sólidos (PEIXOTO FILHO e OLIVEIRA, 2008). De acordo com Odum (1988), a acelerada urbanização e crescimento das cidades, promoveram mudanças fisionômicas no planeta. À medida que há uma evolução tecnológica, agregam-se novos hábitos e costumes à sociedade, gerando novas fontes de poluição com consequentes problemas relativos ao seu tratamento (TABALIPA e FIORI, 2006).

Tabalipa e Fiori (2006) revelaram que apesar dos termos "lixo" e "resíduos sólidos" serem muitas vezes utilizados com o mesmo significado possuem conceitos diferentes. Para Ferreira (1999), lixo é tudo aquilo que não se quer mais e se joga fora; coisas inúteis, velhas e sem valor. De acordo com Associação de Brasileira de Normas Técnicas (ABNT, 2004), os resíduos podem ser definidos nos estados sólido e semissólido, que resultam de atividades de diversas origens e são classificados quanto aos riscos potenciais gerados ao meio ambiente e à saúde pública.

A população brasileira opta pelo ecossistema urbano como lar (MUCELIN e BELLINI, 2008). Segundo o Instituto Brasileiro de Geografia e Estatística (IBGE, 2000), no Brasil cerca de $80 \%$ das pessoas são moradores urbanos e diariamente mais de 228 mil toneladas de resíduos sólidos são coletados no país. Somente na região Norte do país, coleta-se cerca de 11 mil toneladas de resíduos por dia e o estado do Amazonas produz cerca de três mil toneladas de resíduos por dia (IBGE, 2000).

O gerenciamento dos resíduos sólidos é fundamental para reduzir os danos causados ao meio ambiente (ERNANDES et al., 2006). No município de Tefé, região do Médio Solimões do Estado do Amazonas, Schor et al. (2007) caracterizaram a falta de gerenciamento e dos resíduos sólidos. A legislação e logística tem tornado difícil a seleção de locais apropriados para o despejo de resíduos sólidos urbanos (LOLLO e GEBERA, 2001). Nos últimos anos, o município tem enfrentado grandes dificuldades em encontrar um local ideal para a destinação correta dos resíduos (SILVA e PINHEIRO, 2010). Este fato tem afetado inclusive a aviação na região. Devido a grande abundancia de urubus, o risco aviário é frequente. Problemas ocasionados pelos resíduos sólidos podem ser evitados através da coleta regular e armazenamento adequado (OLIVEIRA e PONTES, 2012).

Segundo Monteiro et al. (2001), a coleta seletiva é o modelo mais empregado nos programas de reciclagem e a formação de cooperativas de catadores é destacada. Para Jóia e Silva (2004), realizar a implantação da coleta seletiva em pequenas comunidades não é tão difícil, desde que haja interesse por parte do governo, empresários e da própria comunidade. Os comportamentos individuais que beneficiam o ambiente são influenciados por valores pessoais de qualidade ambiental e normas sociais (VISCUSI et al., 2011). É fundamental a participação da sociedade nas questões relacionadas à disposição final dos resíduos sólidos, passando por um processo de educação ambiental e campanhas informativas quanto aos benefícios oferecidos (TABALIPA e FIORI, 2006).

De acordo com o Manual de Educação de Consumo Sustentável (2005), a reciclagem é uma das alternativas mais vantajosas. O Instituto de Pesquisa Econômica Aplicada (IPEA, 2010), destacou que a reciclagem proporciona benefícios ambientais e econômicos. Segundo Tabalipa e Fiori (2006), são de extrema importância a reciclagem e o aproveitamento dos resíduos sólidos, mantendo o meio ambiente saudável e também proporcionando a geração de trabalho e renda. Além da reciclagem, a compostagem é fundamental para obtenção de fertilizantes orgânicos, sendo um agente importante para gestão ambiental sustentável (ABREU-JUNIOR et al., 2012).

Neste estudo foi verificado o potencial benefício econômico dos resíduos sólidos descartados por residências e comércios, através de sua categorização e quantificação. Avaliou-se o conhecimento dos residentes e comerciantes sobre resíduos sólidos, seus benefícios e impactos 
ambientais. Foram identificados, também, os órgãos e instituições que realizam trabalhos ou projetos envolvendo a coleta seletiva.

\section{MATERIAL E MÉTODOS}

A cidade de Tefé possui uma área de $23.705 \mathrm{~km}^{2}$ com altitude média de $47 \mathrm{~m}$ acima do nível do mar, localiza-se no centro do estado do Amazonas, no médio rio Solimões, às margens do lago que recebe o mesmo nome (SILVA e PINHEIRO, 2010). A sua sede dista $633 \mathrm{~km}$ por via fluvial de Manaus (GONTIJO et al., 2005). Segundo os dados do IBGE (2010), o número de residências é de 12.165, sua população é de 61.453 habitantes, sendo que 50.069 pessoas ocupam a área urbana e 11.384 abrange a área rural. No presente estudo apenas a área urbana de Tefé foi estudada.

De acordo com um mapa obtido pelo Google Earth (2008), o município de Tefé possui um total de 114 ruas. Durante os meses de setembro e outubro foram sorteadas 60 ruas, ou seja, mais da metade das ruas fizeram parte da pesquisa. Este tamanho amostral foi calculado considerando-se o número de habitantes da área urbana de Tefé (50.069), qui-quadrado ao nível de significância de 90\% (2,706), intervalo de confiança de 0,1 e 0,5 como parâmetro populacional segundo metodologia proposta por BERNARD (1995). Em cada rua sorteada, uma residência e um comércio foram escolhidos ao acaso e tiveram seus resíduos classificados e quantificados de acordo com a tabela de Pessin et al. (2002). O processo de separação, classificação e pesagem ocorreu apenas uma vez em cada local visitado. Para a pesagem dos resíduos foi utilizada uma balança comercial com capacidade para 20 quilogramas e precisão de \pm 10 gramas. A coleta de dados em campo ocorreu entre os meses de julho a outubro de 2013.

A quantidade média de resíduos produzido por residência foi obtida dividindo o peso total produzido por residência pelo número de residências visitadas (60). Para se calcular a quantidade de habitantes por residência, o número total de habitantes do município (61.453) foi dividido pelo número de residências (12.165) (IBGE, 2010). Dividindo-se o peso do resíduo produzido por cada residência pelo número médio de habitantes em cada moradia obteve-se uma estimativa do valor máximo de resíduos produzido por cada habitante por dia ( $\mathrm{kg} / \mathrm{hab}$./dia). Um segundo método utilizado para estimar a produção diária de resíduos produzidos por residência foi dividir o total de resíduos coletado diariamente pelo serviço de coleta municipal pelo número de habitantes da cidade. Para isso foram utilizados os dados sobre a produção total diária de resíduos sólidos (30 t/dia), cedidos pela Secretaria Municipal de Meio Ambiente (SEMMA) (Tabela 2).

Para se calcular o potencial econômico dos resíduos produzidos em Tefé a massa total de resíduos produzidos por mês, estimado no presente estudo e também divulgado pela SEMMA, foi dividido proporcionalmente às categorias de Pessin et al. (2002) e o resultado multiplicado pelo seu valor de mercado, obtido na empresa de compra de material reciclável "Point da Sucata" localizada no município de Tefé, Tabalipa e Fiori (2006) e no IPEA (2010).

Ao final de todo o processo de categorização e pesagem dos resíduos, cada residente e comerciante participou de uma entrevista tendo como base um formulário de perguntas criados a partir dos principais temas que abrangem resíduos sólidos, seus potenciais benefícios e possíveis impactos ambientais.

Também foram realizadas, no mês de agosto de 2013, entrevistas em secretarias, instituições, empresas e outros que poderiam ter trabalhos, projetos ou campanhas com coleta seletiva e recolhimento de materiais recicláveis. 


\section{RESULTADOS E DISCUSSÃO}

Dentre o total de resíduos produzidos, pelas residências e comércios $53,4 \%$ são recicláveis e $46,6 \%$ não são recicláveis. Foram encontrados, em média, $3,36 \mathrm{~kg}(D P=2,56 \mathrm{~kg})$ e $3,00 \mathrm{~kg}(D P=$ $2,24 \mathrm{~kg}$ ) de resíduos recicláveis e não recicláveis, respectivamente, nas 60 residências amostradas. Estes valores ficaram próximos dos valores médios obtidos nos comércios: $3,41 \mathrm{~kg}(D P=3,39 \mathrm{~kg})$ de material reciclável e $2,92 \mathrm{~kg}(D P=2,86 \mathrm{~kg})$ de material não reciclável. Monteiro et al. (2001) revelaram que os resíduos recicláveis são os materiais orgânicos, papel, plástico, vidro e metal. Desta forma, percebe-se que a maior parte de resíduos sólidos produzidos podem ser reciclados (Tabela 1).

Tabela 1 - Massa total (em kg) e porcentual (entre parênteses) dos resíduos encontrados em 60 residências e 60 comércios na área urbana de Tefé entre setembro e outubro de 2013.

\begin{tabular}{lccc}
\hline Categoria de resíduo sólido & Residências & Comércios & $\begin{array}{c}\text { Total de cada } \\
\text { categoria }\end{array}$ \\
\hline Favoráveis à reciclagem & & & $\mathbf{1 4 2 , 1}(\mathbf{1 8 , 7})$ \\
Matéria orgânica putrescível & $98,5(25,9)$ & $43,6(11,5)$ & $\mathbf{9 8 , 8}(\mathbf{1 3 , 0})$ \\
Papel e papelão & $31,6(8,3)$ & $67,2(17,7)$ & $\mathbf{7 5 , 8}(\mathbf{1 0 , 0})$ \\
Plástico & $37,5(10,0)$ & $38,3(10,0)$ & $\mathbf{6 8 , 4}(\mathbf{9 , 0})$ \\
Vidro & $26,5(7,0)$ & $41,9(11,0)$ & $\mathbf{2 0 , 5}(\mathbf{2 , 7})$ \\
Metal não-ferroso & $7,2(2,0)$ & $13,3(3,5)$ & $\mathbf{4 0 5 , 6}(\mathbf{5 3 , 4})$ \\
Subtotal & $\mathbf{2 0 1 , 3 ( 5 3 , 2 )}$ & $\mathbf{2 0 4 , 3}(\mathbf{5 3 , 7})$ & \\
\hline Não favoráveis à reciclagem & & & $\mathbf{6 7 , 2}(\mathbf{8 , 9})$ \\
Pedra, terra e cerâmica & $31,2(8,2)$ & $36,0(9,5)$ & $\mathbf{6 6 , 0}(\mathbf{8 , 7})$ \\
Madeira & $34,2(9,0)$ & $31,8(8,4)$ & $\mathbf{6 3 , 7}(\mathbf{8 , 4})$ \\
Diversos & $30,4(8,0)$ & $33,3(8,8)$ & $\mathbf{5 5 , 7}(\mathbf{7 , 3})$ \\
Panos, trapos, couro e borracha & $31,0(8,0)$ & $24,7(6,5)$ & $\mathbf{4 7 , 4}(\mathbf{6 , 2})$ \\
Contaminante biológico & $22,5(5,9)$ & $24,9(6,6)$ & $\mathbf{3 7 , 2}(\mathbf{4 , 9})$ \\
Contaminante químico & $20,3(5,3)$ & $16,9(4,5)$ & $\mathbf{1 6 , 9}(\mathbf{2 , 2})$ \\
Metal ferroso & $9,2(2,4)$ & $7,7(2,0)$ & $\mathbf{3 5 4 , 1}(\mathbf{4 6 , 6})$ \\
Subtotal & $\mathbf{1 7 8 , 8}(\mathbf{4 6 , 8})$ & $\mathbf{1 7 5 , 3}(\mathbf{4 6 , 3})$ & $\mathbf{7 5 9 , 7}$
\end{tabular}

A maior quantidade de resíduos produzidos, considerando-se a soma de residências e comércios, ocorre no item matéria orgânica putrescível com 18,7\% (Tabela 1). Este tipo de resíduo passa por um processo natural de decomposição biológica resultando em adubo (MONTEIRO et al., 2001). As usinas de triagem que realizam esse trabalho geralmente recolhem o material diretamente dos aterros e lixões sem utilizar da compra por catadores (PEIXOTO FILHO e OLIVEIRA, 2008).

No Plano Municipal de Gestão Integrada de Resíduos Sólidos do Município de Tefé (AMAZONAS, 2012), está prevista a implantação do Centro Integrado de Resíduos Sólidos - CIRS que possui procedimento para tratar o lixo orgânico através da compostagem. O lixo orgânico desperdiçado pode ser uma alternativa eficiente para a nutrição de terra para plantio, podendo ser utilizado como adubo (SILVA et al., 2012). Com a falta do CIRS muito lixo orgânico ainda é desperdiçado, sendo depositado no lixão do município, quando poderia estar sendo utilizado como adubo na agricultura.

No presente estudo foi estimado que cada residência produz cerca de $6,3 \mathrm{~kg} / \mathrm{residência} / \mathrm{dia}$ e que cada habitante produz cerca de $1,3 \mathrm{~kg} / \mathrm{hab}$./dia, desta forma, a área urbana de Tefé produz cerca de 65,1 t/dia. O secretário da Secretaria Municipal de Meio Ambiente - SEMMA (Afonso Celso 
Candeira Valois, comunicação pessoal) informou, no entanto, que o município produz cerca de 30 t/dia de lixo, ou seja, cerca de $0,6 \mathrm{~kg} / \mathrm{hab}$./dia de lixo urbano. Técnicos de gerenciamento integrado de resíduos sólidos consideraram uma faixa de variação média de 0,4 a $0,7 \mathrm{~kg} / \mathrm{hab}$./dia no Brasil (OBLADEN, 2004), valores estes mais próximos do estimado a partir dos dados da SEMMA do que os dados do presente estudo.

Para Bezerra (2000), entretanto, este valor pode chegar até 2,5 kg/hab./dia, dependendo da sociedade, hábitos e padrão de vida. A diferença no total de lixo produzido diariamente encontrado no presente estudo e divulgada pela prefeitura deve-se ao pressuposto inicial de que o lixo analisado neste estudo representa a produção diária de uma residência. Como a frequência em que os moradores descartam o seu lixo para ser recolhido pelo setor de limpeza pública é variável, o lixo analisado pode ter sido acumulado por mais de um dia nas residências. A diferença dos dados apresentados também pode ser justificada pelo fato de que alguns moradores optam por jogar seu lixo diretamente no lixão, evitando o recolhimento pela prefeitura.

Tabela 2 - Demonstrativo do potencial benefício econômico gerado pelos resíduos favoráveis à reciclagem produzidos pelas residências na área urbana de Tefé. Valores mínimos obtidos por dados da Secretaria de Meio Ambiente e máximo a partir dos dados coletados do presente estudo.

\begin{tabular}{|c|c|c|c|c|c|}
\hline \multirow{2}{*}{ Categoria } & \multicolumn{2}{|c|}{ Peso (t/residência/mês) } & \multirow{2}{*}{$\begin{array}{c}\text { Preço de venda } \\
(\mathrm{R} \$ / \mathbf{k g})\end{array}$} & \multicolumn{2}{|c|}{ Valor Total (R\$) } \\
\hline & Mínimo & Máximo & & Mínimo & Máximo \\
\hline Plástico & 90 & 195 & 0,60 & $54.000,00$ & $117.000,00$ \\
\hline Metal não-ferroso (Alumínio) & 18 & 39 & 2,20 & $39.600,00$ & $85.800,00$ \\
\hline Papel / Papelão & 75 & 162 & 0,26 & $19.500,00$ & $42.120,00$ \\
\hline Vidro & 63 & 137 & 0,07 & $4.410,00$ & $9.590,00$ \\
\hline Total & 246 & 533 & & $\mathbf{1 1 7 . 5 1 0 , 0 0}$ & $254.510,00$ \\
\hline
\end{tabular}

Os resíduos sólidos recicláveis podem proporcionar ganhos econômicos mensais de no mínimo $\mathrm{R} \$ 117.510,00$ até $\mathrm{R} \$ 255.150,00$ para o município (Tabela 2). Este dinheiro poderia beneficiar Cooperativas de Catadores, cuja implantação é prevista como "econegócio" no Plano Municipal de Resíduos Sólidos de Tefé (AMAZONAS, 2012), ou servir para a compra de materiais, equipamentos e transporte, para os resíduos produzidos em Tefé possam ser enviados às empresas recicladoras em Manaus.

Considerando-se que em Tefé 6.268 pessoas vivem com menos de meio salário mínimo per capita (IBGE, 2013) um projeto que estimule cooperativas de separação dos resíduos poderia beneficiar aproximadamente 80 pessoas com um salário mínimo mensal, com direitos trabalhistas assegurados, apenas com o dinheiro obtido pela estimativa mais conservadora.

Para Kirchner et al. (2009), os catadores realizam um trabalho de modo a ingressar no mundo social, além da importante colaboração para a sociedade, gerando emprego e renda, e também para o meio ambiente, diminuindo a exploração de recursos naturais e o descarte de resíduos nos lixões e aterros sanitários ou controlados.

De acordo com D’Almeida e Vilhena (2000), o reaproveitamento dos resíduos reduz o volume que se destina ao lixão, aterro sanitário ou controlado. Para Tabalipa e Fiori (2006), menos material sendo descartado, aumenta a vida útil do lixão ou aterros. Este propósito pode ser voltado ao futuro aterro sanitário do município de Tefé. $\mathrm{O}$ atual aterro controlado está quase cheio e o município tem dificuldade para encontrar um novo local para a construção de um aterro sanitário, apesar do estudo de Silva e Pinheiro (2010) apontar alguns possíveis locais.

Para analisar o conhecimento da população de Tefé sobre o problema do lixo foram entrevistados 120 moradores. Dentre eles 44 foram do sexo feminino e 76 do sexo masculino com idade média de 33,7 (DP = 15,2; 16-74) e 40,9 ( $\mathrm{DP}=14,3 ; 19-74)$ anos, respectivamente. Quanto 
ao nível de instrução 32 possuíam ensino fundamental, 55 possuíam ensino médio, 18 possuíam ensino superior e 15 não possuíam instrução escolar. Os moradores com origem local compuseram a maioria dos entrevistados $(82,5 \%)$, os imigrantes de outras cidades da região Norte $13,1 \%$, da região Sudeste $2 \%$, da região Nordeste $0,8 \%$, da região Centro Oeste $0,8 \%$, e da região Sul 0,8\%.

Grande parte dos entrevistados mostrou não saber o que é resíduo sólido tanto entre os comerciantes $(81,7 \%)$ quanto entre os residentes $(85,0 \%)$. Analisando-se as respostas por grau de escolaridade (Figura 1) torna-se perceptível que este desconhecimento é maior entre aqueles entrevistados que se declararam analfabetos ou que estudaram até o nível fundamental.

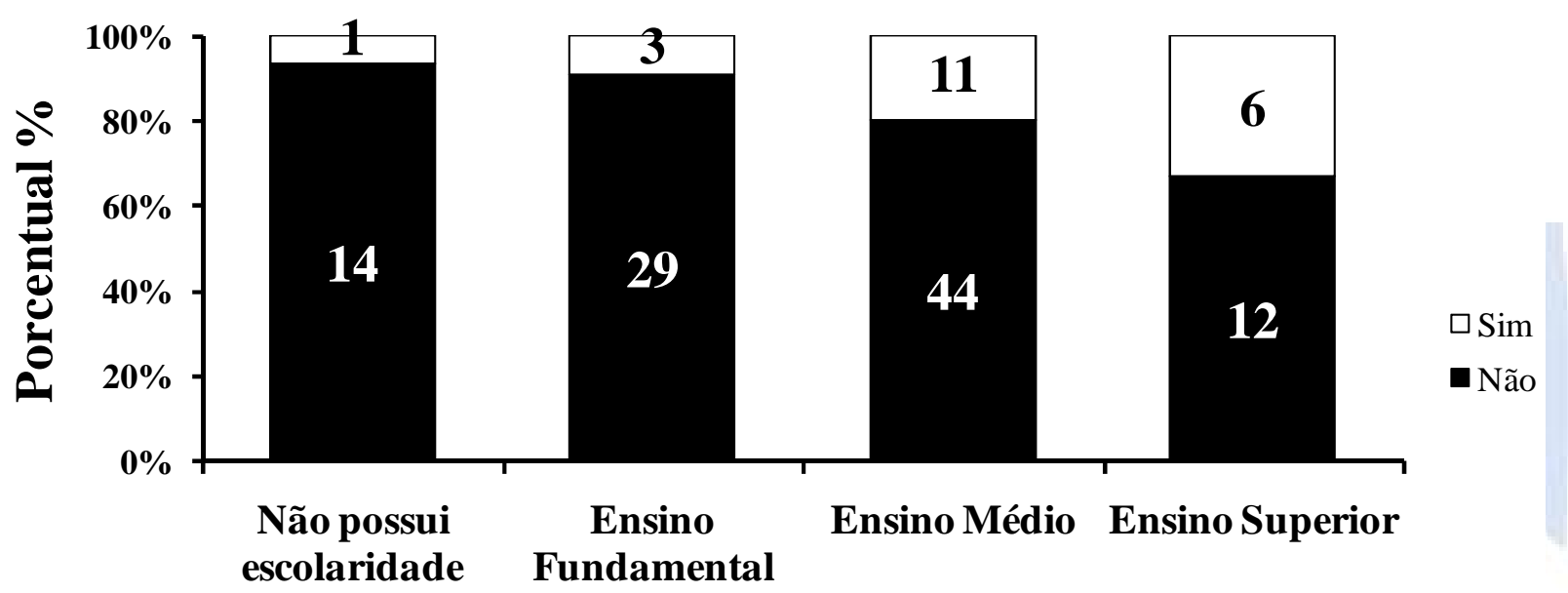

\section{Graus de Escolaridade}

Figura 1. Respostas de residentes e comerciantes quanto ao conhecimento sobre o que são resíduos sólidos entre diferentes graus de escolaridade. Os números nas colunas são o total de respostas.

A educação ambiental pode favorecer no conhecimento e informação sobre o conceito de resíduo sólido e seus tratamentos nos diferentes graus de escolaridade, constituindo-se em um primeiro e importante passo para a solução do problema. D'Almeida e Vilhama (2000) consideraram a educação ambiental fundamental no conhecimento e atitudes voltados para a conservação do meio ambiente.

Os resíduos produzidos nas residências e comércios são armazenados de diferentes maneiras, dentre os principais tipos de armazenamento destacam-se as sacolas plásticas, caixas de papelão, caixas improvisadas e baldes (Figura 2). De acordo com Monteiro et al. (2001), o armazenamento adequado dos resíduos produzidos é de suma importância, pois evita acidentes, proliferação de vetores, minimiza o impacto ambiental e olfativo e facilita a coleta. Tal ação é tão importante que o Plano Municipal de Resíduos Sólidos (AMAZONAS, 2012) prevê a implantação da regulamentação de armazenadores e coletores para comércios que vendem pilhas, baterias pneus, e outros onde possam ser devolvidos os materiais já utilizados sem autonomia. Esta ação ainda não ocorre no município. Contaminantes químicos ainda são armazenados irregularmente e descartados no lixão pelas residências e comércios com 4,9\% dos resíduos produzidos (Tabela 1).

Dentre os comerciantes entrevistados, 55,0\% acham que a prefeitura é responsável pelo gerenciamento do lixo, 21,7\% responderam Secretaria de Meio Ambiente, 16,7\% não sabem. Apenas 3,3\% acham que a população é responsável pelo gerenciamento, $1,7 \%$ responderam Secretaria de Infraestrutura e 1,7\% não têm certeza.

Os residentes entrevistados afirmam, com 50,0\% das respostas, que a prefeitura é a responsável pelo gerenciamento dos resíduos sólidos, 23,3\% respondeu Secretaria de Meio 
Ambiente, 13,3\% não sabem, 6,7\% diz que a população é responsável, 3,3\% respondeu Secretaria de Infraestrutura e 3,3\% não têm certeza.

Considerando-se que as secretarias do meio ambiente e de infraestrutura também fazem parte da prefeitura, pode-se dizer que a maioria esmagadora dos entrevistados concorda com a responsabilidade do poder público municipal para a gestão do lixo. Embora constitucionalmente isto sejam verdade, um programa de coleta seletiva de lixo e mesmo o descarte correto de resíduos contaminantes é responsabilidade do cidadão. Cabe aos programas de educação ambiental de Tefé, portanto, adotar uma estratégia na qual o cidadão comum internalize a sua responsabilidade quanto à questão do lixo e passe a contribuir para a sua solução.

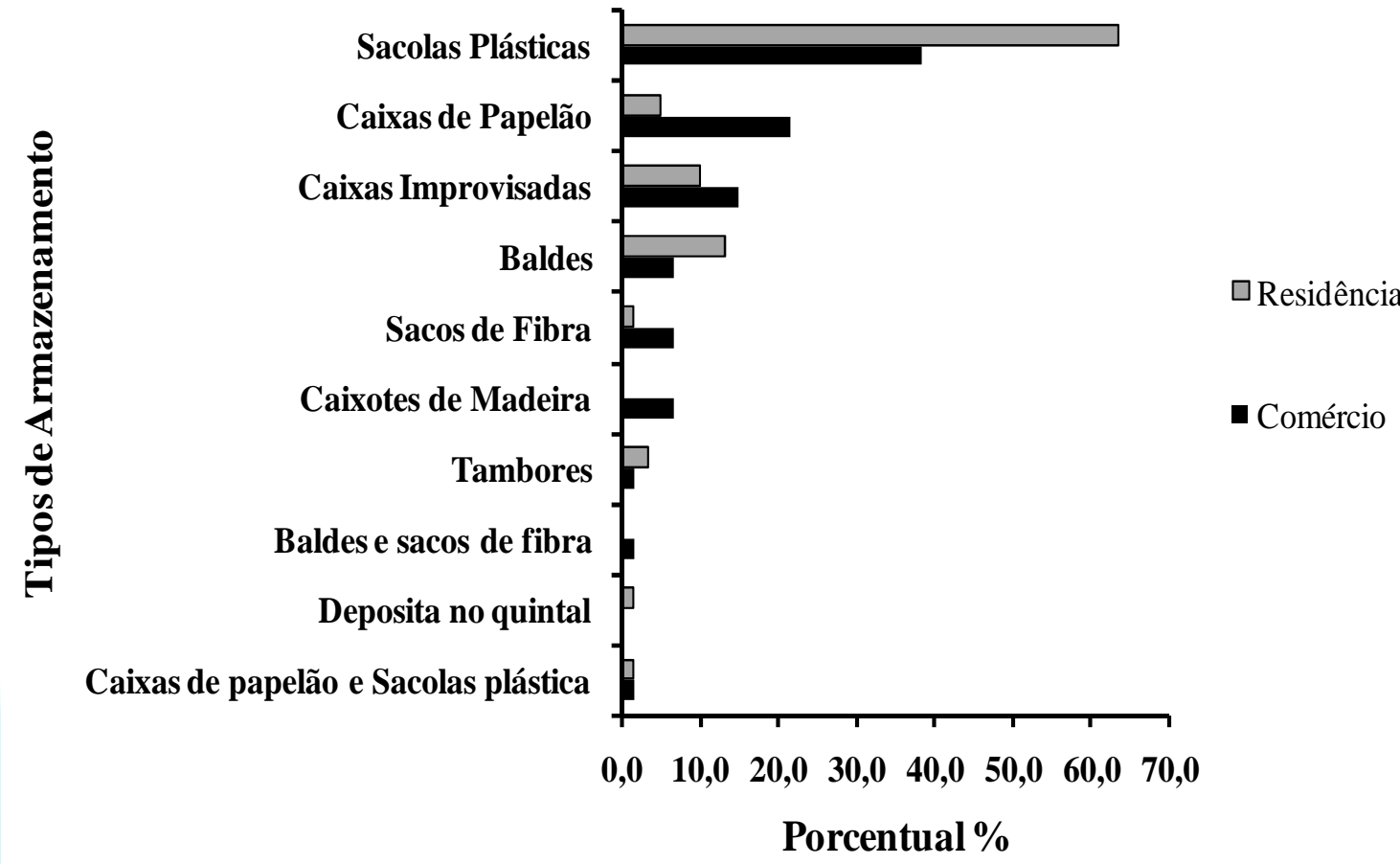

Figura 2. Armazenamento do lixo produzido pelas residências e comércios.

A maior parte dos entrevistados não tem o conhecimento dos tipos de benefícios que o seu lixo descartado poderia gerar, a resposta que surgiu com mais frequência foi não sabe, seguindo de benefício econômico e ecológico (Figura 3).

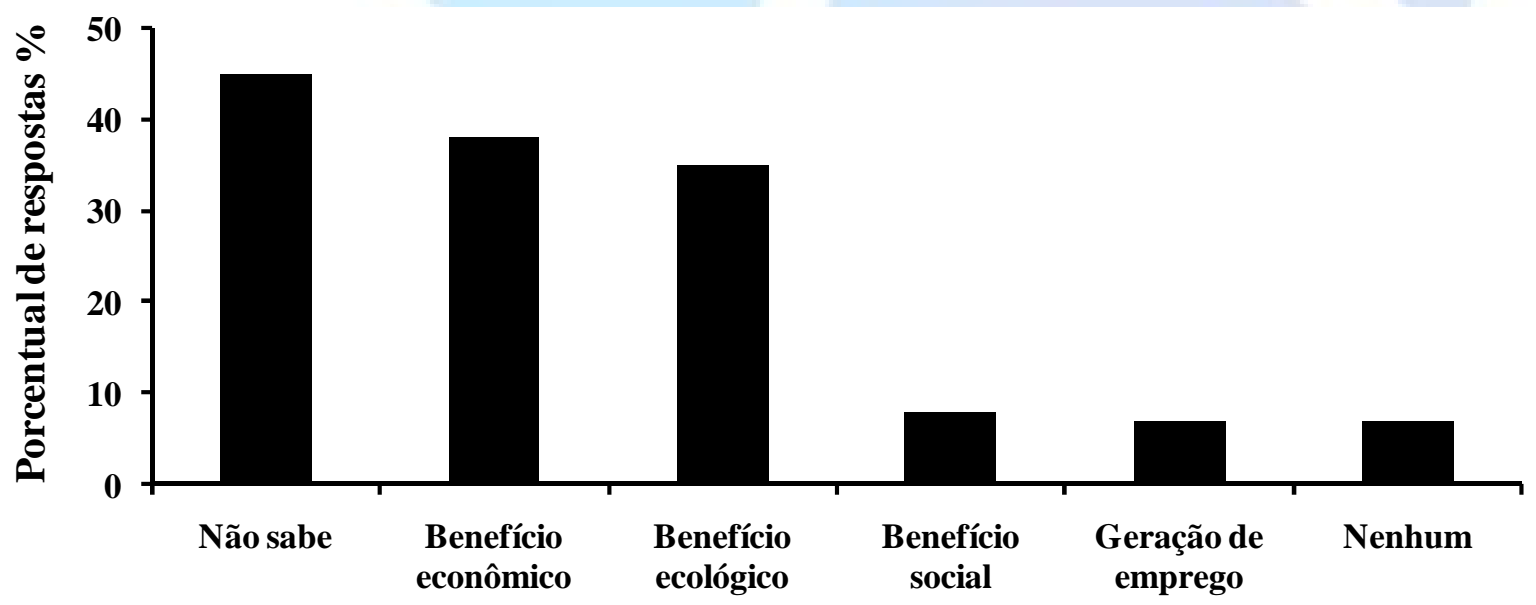

Respostas mais frequentes

Figura 3. Respostas dos residentes e comerciantes quanto a expectativa do aproveitamento do lixo. 
De acordo com Plano Municipal de Resíduos Sólidos (AMAZONAS, 2012), é de total responsabilidade da Prefeitura Municipal, com participação das Secretarias de Infraestrutura e Meio Ambiente, a execução dos serviços de gerenciamento, coleta e transporte dos resíduos sólidos. Quanto aos benefícios que podem ser gerados, Monteiro et al. (2001) destacou que a reciclagem gera principalmente benefícios ambientais. Para Tabalipa e Fiori (2006), o benefício econômico se destaca através da renda obtida pela venda dos materiais recicláveis, ou dos produtos gerados pela reciclagem.

O beneficio econômico, por algum motivo, é mais frequentemente lembrado nas respostas que o benefício ecológico. De acordo com Oliveira e Zanin (2011), a geração de trabalho e renda para aqueles desempregados surgem através da economia solidária, que tem o papel de fornecer alternativas de trabalhos, favorecendo aqueles excluídos do mercado capitalista. Desta forma, os programas de reciclagem seriam uma alternativa, pois segundo Monteiro et al. (2001), cooperativas de catadores oferecem vantagens como geração de emprego e renda.

Quando perguntado aos entrevistados sobre o conhecimento de alguma ação no município que reaproveite o lixo, 70,0\% deles não conheciam nenhuma ação de reaproveitamento de lixo. Outros $15,0 \%$ mencionaram o Point da Sucata, empresa que compra de catadores alguns materiais recicláveis para revenda. É importante destacar que 6,7\% declararam não saber, mas afirmaram que o Instituto de Desenvolvimento Sustentável Mamirauá - IDSM estaria realizando algum trabalho ou projeto com relação ao reaproveitamento de lixo. O Exército Brasileiro e o Centro de Estudos Superiores de Tefé também foram citados com 4,2 e 2,5\% das respostas respectivamente. Os outros $1,6 \%$ não tiveram certeza da resposta.

Segundo a Associação Brasileira de Empresas de Limpeza Pública e Resíduos Especiais (ABRELPE, 2009), grande parte dos municípios pequenos do Brasil não adota a iniciativa de coleta seletiva, contudo, na região Norte do país, os indicativos demonstram um pequeno crescimento na quantidade de municípios que estão adotando a coleta seletiva.

Esse leve crescimento é resultado de pontos de entrega voluntária ou dos convênios com cooperativas de catadores para a execução dos serviços. Em Tefé, a empresa Point da Sucata destaca-se como ponto principal de compra de alguns materiais recicláveis. O CEST/UEA que realiza atualmente o Projeto Cidade Limpa é ponto de entrega de alguns materiais como garrafas PET, latinhas de alumínio, pilhas e baterias.

Quando perguntado o que é impacto ambiental, a maior parte dos entrevistados, dentre residentes e comerciantes, associou os impactos ambientais aos danos causados à natureza (Figura 4). Percebe-se que o termo, impacto ambiental, não é muito comum para os residentes e comerciantes entrevistados, sendo que boa parte das respostas foi "não sei". O lixo como causador de impacto ambiental foi o menos lembrado.

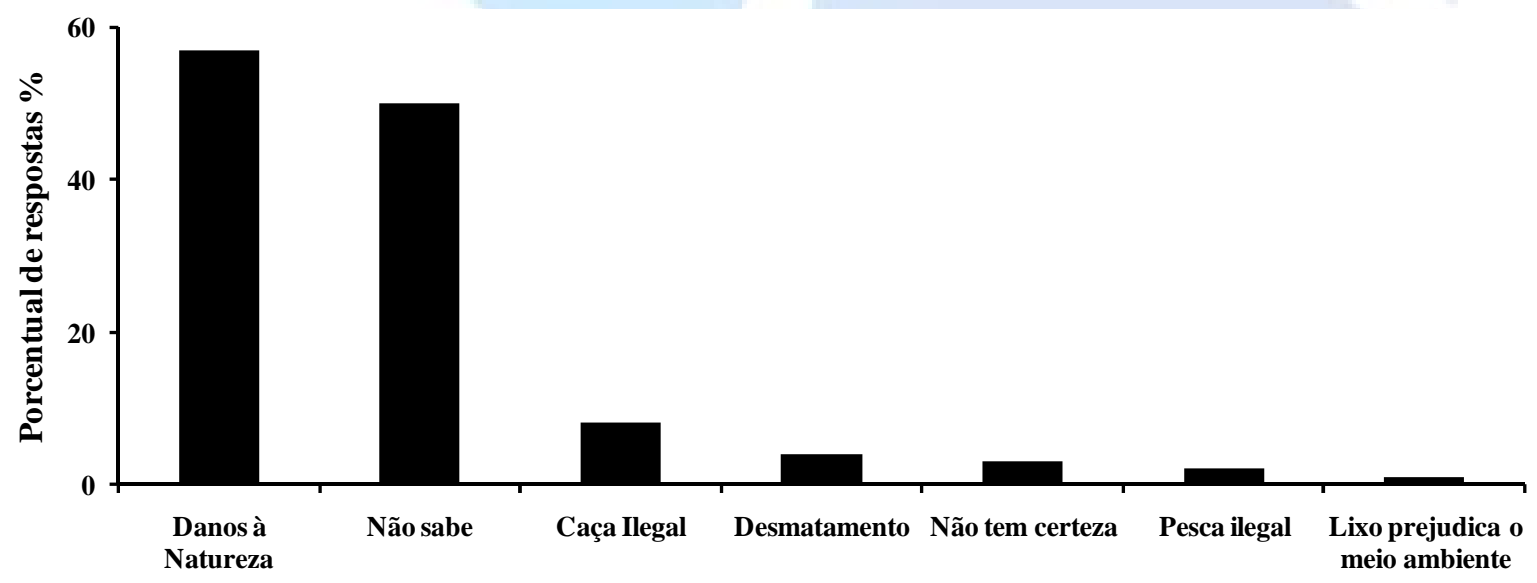

Respostas mais frequentes

Figura 4. Conhecimento dos residentes e comerciantes sobre o que é impacto ambiental. 
Para Mucelin e Bellini (2008), o lixo urbano é um dos maiores responsáveis pelos impactos ambientais, dentre eles destacam-se a prática inadequada de disposição dos resíduos sólidos, como por exemplo, margens de ruas e cursos de água. De acordo com Monteiro et al. (2001), o gerenciamento integrado dos resíduos sólidos buscam alternativas necessárias para reduzir os impactos ambientais decorrentes dos resíduos. Desta forma, políticas públicas devem envolver a coleta seletiva, pois se considera uma prática imprescindível ao alcançar a sustentabilidade e minimizar os impactos ambientais (MUCELIN e BELLINI, 2008).

Pode-se perceber que grande parte dos residentes e comerciantes não têm o conhecimento dos impactos ambientais causados pelo lixo (Figura 5). Quando perguntados pelos impactos ambientais causados pelo lixo, a maioria respondeu não saber, os demais descreveram algumas consequências causadas pelos resíduos sólidos, dentre as quais algumas pertinentes (contaminação dos rios, proliferação de doenças/pragas/urubus/cachorros), algumas um tanto vagas (degradação do meio ambiente, sujeiras, morte dos animais) e outras apenas indiretamente associadas ao descarte incorreto de resíduos (degradação da floresta e efeito estufa).

Os moradores urbanos procuram um ambiente saudável para viver, onde a poluição seja mínima, com água pura e abundante, além de outras características ditas fundamentais de um ambiente saudável de se viver (MUCELIN e BELLINI, 2008). Desta forma, os recursos naturais tendem a ficar cada vez mais escassos, devido às consequências de seu uso inadequado. Portanto, é necessário que se assuma responsabilidades ainda maiores com os cuidados da natureza (CAVALCANTI et al., 2011). Para que comportamentos responsáveis façam parte do cotidiano do morador da cidade, torna-se fundamental que o cidadão conheça como o problema do lixo interfere nos processos ecológicos, urbanos e adjacentes.

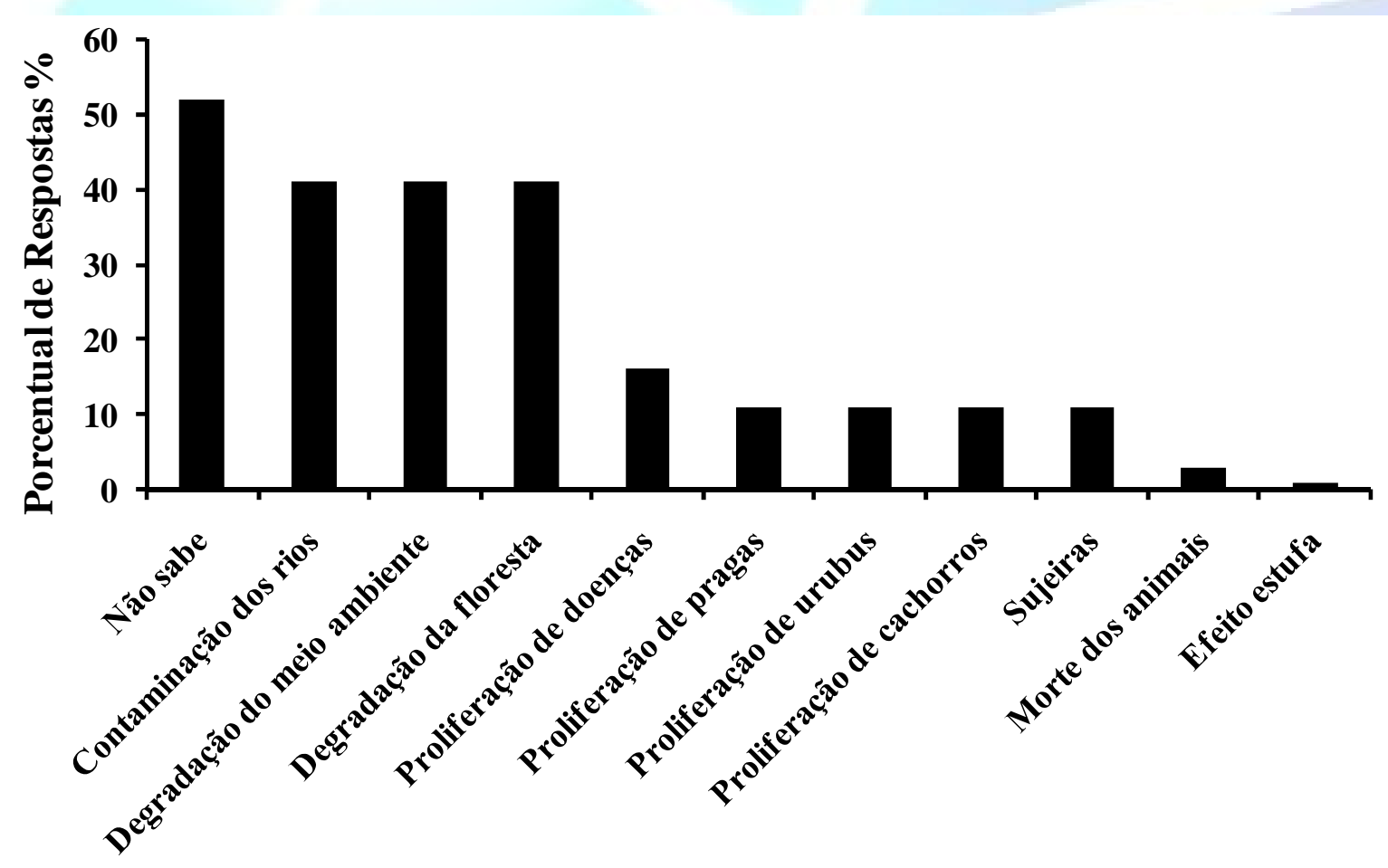

\section{Respostas frequentes}

Figura 5. Frequência de respostas dos residentes e comerciantes sobre os possíveis impactos ambientais causados pelo lixo. 
Dentre os residentes e comerciantes, $43,3 \%$, demonstram não saber que tipo de ação deve ser tomado para reduzir os impactos ambientais (Figura 6). Fiscalização e punição por ações criminosas; ação da prefeitura e da população foram as respostas mais frequentes quanto as ações de redução aos impactos ambientais.

Para Jardim e Wells (1995), o gerenciamento do lixo residencial e comercial é de total responsabilidade da prefeitura, enquanto outros são de responsabilidade do próprio gerador. Como suporte, algumas administrações municipais podem agir como órgãos de fiscalização, assim como também, empresas terceirizadas no apoio de coordenação e planejamento, para que os impactos ambientais sejam os mínimos possíveis (MONTEIRO et al., 2001).

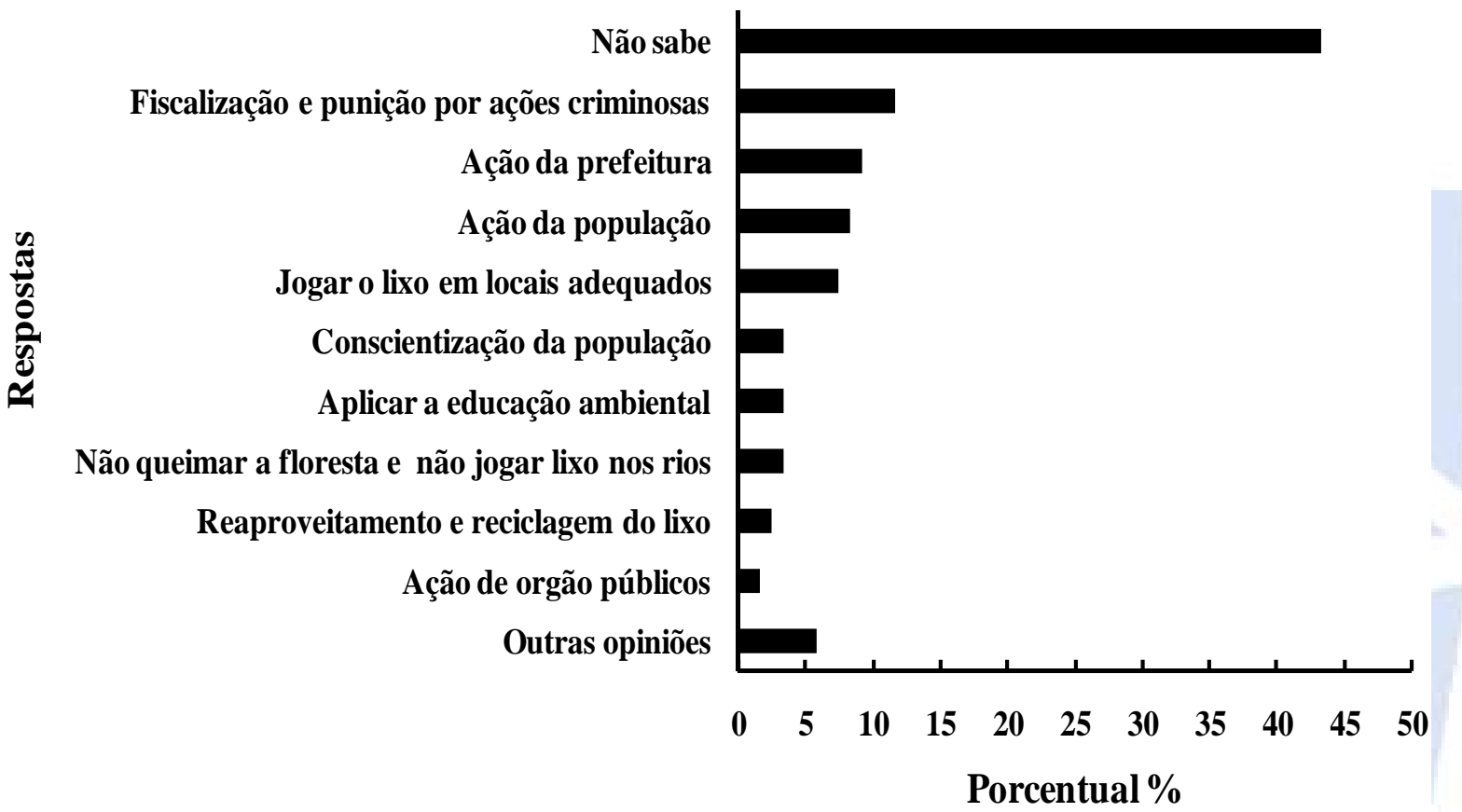

Figura 6. Porcentual dos tipos de ações, que segundo os residentes e comerciantes podem ser tomadas para reduzir os impactos ambientais.

Os órgãos e instituições visitados foram: ICMBio, Secretaria de Municipal de Meio Ambiente, Exército, Point da Sucata, Força Aérea Brasileira, Aeroporto de Tefé, CEST e Instituto de Desenvolvimento Sustentável Mamirauá.

O Exercito, CEST e Mamirauá são os órgãos que executam trabalhos e projetos quanto ao aproveitamento de lixo. O Exercito possui diferentes planos quanto à gestão ambiental, economia de energia, coleta de óleo em água da lavagem de veículos e gerenciamento de resíduos sólidos. O CEST possui o Projeto "Cidade Limpa", ainda em fase inicial, que propõe a coleta seletiva, educação ambiental e reciclagem para o município.

No Mamirauá existem pequenas iniciativas de coleta seletiva de pilhas e cartuchos de impressoras. As demais instituições não possuem outros tipos de trabalhos de aproveitamento de lixo, com exceção da empresa Point da Sucata que compra alguns materiais como alumínio, cobre e metal de catadores para ser revendido em Manaus.

Desde os primeiros programas de coleta seletiva em 1980 no Brasil, as empresas, indústrias e instituições se mobilizam na separação e classificação de seus resíduos sólidos produzidos (CAVALCANTI et al., 2011). De acordo com o Manual de Educação de Consumo Sustentável (2005), as empresas, por exemplo, com relação à sociedade e meio ambiente devem agir de forma 
responsável em todas as suas atividades produtivas. Estas atividades de responsabilidade contribuem para a construção de sociedades sustentáveis.

Dentre as principais dificuldades para por em prática projetos de aproveitamentos de lixo, destaca-se a falta de materiais e recursos, logística, consciência e mentalidade individual, destino final do lixo, auxílio e apoio financeiro.

De acordo com Monteiro et al. (2001), a implantação de programas e projetos de coleta seletiva e reciclagem é necessária além de recursos, o aprimoramento e a capacitação de administrações para enfrentar os problemas. Para a IPEA (2010), é necessário usar da criatividade para contornar as dificuldades e implantar políticas que garantam maior estabilidade aos projetos de reciclagem.

Os benefícios que foram destacados pelas instituições, em sua maior parte, foram voltados para o saneamento básico, para a sociedade e meio ambiente, além de gerar emprego e renda e evitar que grandes quantidades de lixo se destinem à natureza prejudicando-a. Em destaque, a professora do CEST, Luciane Lopes, destacou em sua resposta sobre a questão, que realizar projetos do tipo, favorece e enriquece a história da sociedade tefeense e demonstra a preocupação do gerenciamento dos resíduos sólidos.

\section{CONCLUSÕES}

De todos os resíduos produzidos, cerca de $27 \%$ podem ser reciclados. Os valores máximos, no entanto, de acordo com os dados desta pesquisa podem ser ainda maiores, pois a produção total de resíduos dos comércios da cidade não foi incluída na estimativa acima. É importante ressaltar que os dados deste estudo equivalem a dois meses, desta forma, é necessário que outros estudos sejam aplicados por períodos mais longos, na qual sejam incluídas ocasiões em que ocorrem festejos e datas comemorativas, onde possivelmente existirá uma maior produção de resíduos sólidos.

Também é necessário que estudos sejam realizados para verificar com que frequência as pessoas descartam seu lixo semanalmente. Este é um fator importante que pode influenciar bastante nos resultados.

O potencial benefício econômico desperdiçado poderia estar sendo usado em favor da própria população, seja por meio de cooperativas ou outros órgãos ou instituições, favorecendo a mesma. O conhecimento da população urbana quanto ao conceito de resíduo sólido e os benefícios que podem ser gerados através da reciclagem podem ser mudados com campanhas e projetos visando o esclarecimento para os diferentes níveis de escolaridade. Incluem-se aqueles que visam apenas os benefícios econômicos. Cabe adicionar a necessidade da educação ambiental, abrangendo os diversos benefícios ecológicos gerados pela reciclagem, tais como: adubo orgânico, hortas coletivas em escolas ou sociedades públicas e privadas e venda de garrafas PET e latinhas de alumínio.

As instituições e órgãos do município realizam poucos trabalhos relacionados à reciclagem. Desta forma, cabe às mesmas executarem trabalhos em conjunto, de modo que o impacto das ações para a reciclagem dos resíduos seja mais efetivo e que proporcionem além do aproveitamento a educação ambiental.

Cabe ao poder público e privado ter a visão de que recursos econômicos estão sendo perdidos, estes esclarecem junto à sociedade o seu papel da parte de um todo para mostrar que o lixo descartado pela população urbana e evidentemente destinado ao lixão do município, pode ser fonte de trabalho, renda e inclusão social para excluídos do mercado de trabalho e ambiente social. $\mathrm{O}$ retorno financeiro que pode ser gerado pelos resíduos sólidos surgiria como incentivo para a inclusão social e conservação do meio ambiente. 


\section{AGRADECIMENTOS}

Ao Centro de Estudos Superiores de Tefé - Universidade do Estado do Amazonas CEST/UEA. Aos professores do colegiado de biologia do CEST Wilsandrei Cella e Cássia Camillo pelas críticas e sugestões. À bióloga e secretária do colegiado de biologia do CEST Ana Caroline Gomes de Lima pelo apoio e sugestões. Aos colegas Edivaldo Lima e Jonylson Pontes pela ajuda no trabalho de campo e sorteio das ruas de Tefé. À empresa Point da Sucata, Exército, Instituto Chico Mendes de Conservação da Biodiversidade-ICMBio, Instituto de Desenvolvimento Sustentável Mamirauá- IDSM, Aeroporto de Tefé - INFRAERO, Força Aérea - DECEA e Secretaria Municipal de Meio Ambiente - SEMMA pelas entrevistas concedidas. Aos residentes e comerciantes do município de Tefé que permitiram a entrada em suas propriedades e colaboraram com as entrevistas. E a todos que colaboraram de forma direta e indireta para a realização deste trabalho.

\section{REFERÊNCIAS}

ABNT, Associação Brasileira de Normas Técnicas. NBR 10004: Resíduos Sólidos - Classificação. Rio de Janeiro, Brasil. 2004, 71 p.

ABRELPE- Associação Brasileira de Empresas de Limpeza Pública e Resíduos Especiais. Panorama de Resíduos Sólidos no Brasil, São Paulo, 2009, 207 p.

ABREU-JUNIOR, C.H.; BOSSO, A.C.; CHITOLINA, J.C.; SILVA, F.C.; BORALLI, K.; WENDEL, C.F. Caracterização de compostos de resíduos sólidos urbanos orgânicos de unidades de conservação de reciclagem e compostagem dos municípios de São Paulo e de São José dos Santos. HOLOS Environment, v.12, n.2, p. 225-240, 2012.

AMAZONAS. Secretaria de Estado de Meio Ambiente e Desenvolvimento Sustentável. Plano Municipal de Gestão Integrado de Resíduos Sólidos de Tefé. Manaus: SDS, 2012, 115 p.

BERNARD, H.R. Social research methods: Qualitative and quantitative approaches. Califórnia: Sage Publications, 360-392 p., 1995.

BEZERRA, L.A.H. Saneamento do meio. Manual de saúde e segurança do trabalho. Florianópolis: Mestra, 499-645 p., 2000.

CAVALCANTI, C.R.; SOUZA, F.C.S.; ALVES, G.S. Estudo do gerenciamento da coleta seletiva dos resíduos sólidos no município de Mossoró-RN. HOLOS,v.4, n.27, p. 51-64, 2011.

D’ALMEIDA, M.L.O.; VILHENA, A. Lixo Municipal: manual de gerenciamento integrado. 2 ed. São Paulo: IPT/CEMPRE, 370 p. 2000.

ERNANDES, A.C.M; GEBERA, D; LOLLO, J.A. Metodologia para levantamento e proposição de alternativas de gerenciamento de resíduos sólidos comerciais. HOLOS Environment, v.8, n.1, p.72-87, 2006.

FERREIRA, A.B. de H. Dicionário Aurélio Básico da Língua Portuguesa. 3 ed. Rio de Janeiro: Nova Fronteira, 2.128 p., 1999. 
GONTIJO, B.M.; SOUZA, A.L. de.; CORREIA, A.F.; ALMEIDA, E.D.; MATTOS, G.C.M. A UFMG e a retomada do projeto Rondon - Ação diagnóstica em Tefé/AM. Universidade Federal de Minas Gerais - UFMG, Belo Horizonte, 7 p., 2005.

GOOGLE EARTH. 2008. KML Gallery: Explore the Earth on Google. Disponível em: <http://earth.google.com/comapi/annotated.html>. Acesso em: 20 ago. 2013.

IBGE, Instituto Brasileiro de Geografia e Estatística. Censo 2000. População urbana brasileira. Disponível em: <http:// www.ibge.gov.br>. Acesso em: 11 juh. 2013.

IBGE, Instituto Brasileiro de Geografia e Estatística. Censo 2010. Número de habitantes do município de Tefé e produção e destino final de resíduos sólidos no Brasil. Disponível em: <http:// www.ibge.gov.br.> Acesso em: 07 juh. 2013.

IBGE, Instituto Brasileiro de Geografia e Estatística. Salário mínimo per capita da população de Tefé. 2013. Disponível em: <http:// www.ibge.gov.br.> Acesso em: 19 jul. 2013.

IPEA - Instituto de Pesquisa Econômica Aplicada. Relatório de Pesquisa sobre Pagamento por Serviços Ambientais Urbanos para Gestão de Resíduos Sólidos. Brasília: IPEA, 63 p., 2010.

JARDIM, N.S.; WELLS, C. Lixo Municipal: Manual de Gerenciamento integrado. São Paulo: CEMPRE, 85 p., 1995.

JÓIA, P.R.; SILVA, M. do S.F. da. Sistema de coleta seletiva dos resíduos sólidos domiciliares produzidos na cidade de Aquidauana. In: IV SIMPÓSIO SOBRE RECURSOS NATURAIS E SOCIOECONÔMICOS DO PANTANAL. Corumbá, MS, 6 p., 2004.

KIRCHNER, R.M.; SAIDELLES, A.P.F.; STUMM, E.M.F. Percepções e perfil dos catadores de materiais recicláveis de uma cidade do RS. Revista Brasileira de Gestão e Desenvolvimento Regional,v.5, n.3, p.221-232, 2009.

LOLLO, J. A. de; GEBERA, D. Tecnologia de Baixo Custo para caracterização de áreas destinadas à disposição de resíduos sólidos urbanos em pequenos municípios. HOLOS Environment, v.1, n.2, p. 127-140, 2001.

MANUAL DE EDUCAÇÃO CONSUMO SUSTENTÁVEL. Brasília: Consumers International/ MMA/ MEC/IDEC, 160 p. 2005.

MONTEIRO, J.H.P.; FIGUEIREDO, C.E.M.F; MAGALHÃES, A.F.; MELO, M.A.F. de; BRITO, J.C.X. de; ALMEIDA, T.P.F. de; MANSUR, G.L. Manual de Gerenciamento Integrado de Resíduos Sólidos. Rio de Janeiro: IBAM, 200 p., 2001.

MUCELIN, C.A.; BELLINI, M. Lixo e impactos ambientais perceptíveis no ecossistema urbano. Sociedade \& Natureza, v.20, n.1, p.111-124, 2008.

OBLADEN, N.L. Curso de aterro sanitário para resíduos sólidos urbanos. Maringá: Centralcon, 2004.

ODUM, E. P. Ecologia. Rio de Janeiro: Guanabara Koogan, 434 p., 1988. 
OLIVEIRA, H. R. B.; PONTES, F. de O. O Risco Aviário e Resíduo Sólido Urbano: a responsabilidade do poder público municipal e as perspectivas futuras. Revista Conexão SIPAER,v.3, n.2, p.189-207, 2012.

OLIVEIRA, M.C. dos S.B. de; ZANIN, M. Economia solidária: uma temática em evolução nas dissertações e teses brasileiras. Revista brasileira de Ciência, Tecnologia e Sociedade,v.2, n.1, p.181-193, 2011.

PEIXOTO FILHO, G.E. da C.; OLIVEIRA, P.T.S. de. Gerenciamento Integrado de Resíduos Sólidos Urbanos Para Município de Pequeno Porte: O estudo de caso de dois irmãos do buriti - MS. Goiás. Revista Eletrônica do Curso de Geografia do Campus Jataí, v.3, p.291-292. 2008.

PESSIN, N.; CONTO, S.M. de; TELH, M; CADORE; J.; ROVATTI, D.; BOFF, R.E.. Diagnóstico preliminar da geração de resíduos sólidos em sete municípios de pequeno porte da região do Vale do Caí, RS. In: SIMPÓSIO INTERNACIONAL DE QUALIDADE AMBIENTAL. Porto Alegre, RS, 6 p., 2002.

SCHOR, T.; COSTA, D.P. da.; OLIVEIRA, J.A. de O. Notas Sobre a Tipificação da Rede Urbana na Calha do Rio Solimões, Amazonas. In: Anais do XII Encontro Nacional da Associação Nacional de Pós-graduação e Pesquisa em Planejamento Urbano e Regional (ANPUR) - Belém, PA, 13 p., 2007.

SILVA, A.A.; COSTA, A.M. da; LANA, R.M.Q. Recycling of nutrients with application of organic waste in degraded pasture. Engenharia Agrícola Jaboticabal, v.56, n.1, p. 53-62, 2012.

SILVA, A.D. da; PINHEIRO, E. da S. A problemática dos resíduos Sólidos Urbanos em Tefé. Sociedade \& Natureza, v.22, n.2, p.297-312, 2010.

TABALIPA, N.L.; FIORI, A.P. Caracterização e Classificação dos Resíduos Sólidos Urbanos do Município de Pato Branco, PR. Revista Brasileira de Ciências Ambientais, v.4: p.23-33, 2006.

VISCUSI, W.K; HUBER, J.; BELL, J. Promoting Recycling: private values, social norms, and economic incentives. American Economic Review: Papers e Proceedings, v.101, n.3, p.65-70, 2011. 